\title{
Random-Parameters Behavioral Models to Investigate Determinants of Perceived Safety in Railway Stations
}

\author{
Pierluigi Coppola $\mathbb{D}^{1},{ }^{1}$ Luigi dell'Olio ${ }^{(D)},{ }^{2}$ and Fulvio Silvestri ${ }^{3}{ }^{3}$ \\ ${ }^{1}$ Politecnico di Milano, Dipartimento di Meccanica, Via G. La Masa 1, Milano 20156, Italy \\ ${ }^{2}$ Universidad de Cantabria, Av. De Los Castros s-n, Santander, Spain \\ ${ }^{3}$ Università di Roma Tor Vergata, Dipartimento di Ingegneria Dell'Impresa, Via Del Politecnico 1, Roma 00133, Italy \\ Correspondence should be addressed to Pierluigi Coppola; pierluigi.coppola@polimi.it
}

Received 2 March 2021; Revised 8 July 2021; Accepted 16 August 2021; Published 24 August 2021

Academic Editor: Hongtai Yang

Copyright ( 2021 Pierluigi Coppola et al. This is an open access article distributed under the Creative Commons Attribution License, which permits unrestricted use, distribution, and reproduction in any medium, provided the original work is properly cited.

\begin{abstract}
Recent studies have highlighted the existence of a gap between actual and perceived safety and have shown that feelings of insecurity can affect individuals' travel behavior before and during the journey. In this paper, a methodology is proposed for assessing determinants of travelers' perception of safety and security in railway stations. The methodological approach includes focus groups, stated preference (SP) surveys, and the estimation of behavioral models with fixed parameters (Binomial Logit) and random parameters (Mixed Logit). The estimation results for a medium-sized railway station (Frosinone, Italy) confirmed that safety and security measures are not equally perceived by individuals and the use of random-parameters models leads to more robust estimates. The proposed modeling approach allows the identification of the interventions that should be prioritized to increase travelers' perceived levels of safety, highlighting those factors, such as, for the considered case study, the presence of security personnel and the level of decorum and maintenance, which are perceived by users as more important than others (e.g., surveillance cameras).
\end{abstract}

\section{Introduction}

Risk perception that involuntary accidents or intentional criminal acts may occur during the journey is one of the main factors that influence an individual's travel choices [1-3]. The former are fears and concerns about falls, collisions, and injuries that fall under the safety sphere, while the latter regards thefts, threats, harassments, and aggressions that fall within security. Both issues can endanger physical and mental human health.

Most researchers focused mobility demand modeling on factors such as time and monetary costs; however, feeling of unsafety and/or insecurity can significantly affect individuals' travel behavior both before starting the journey (pretrip, e.g., in choosing the destination, transport mode, and time of departure/arrival) and during the journey (en route, e.g., in choosing the route, whether to board on a vehicle, and where to wait). In fact, some may a priori not consider a certain mode of transport as it is associated with a high chance of unpleasant events, just as some may avoid going to a terminal at certain times of the day (early in the morning or at night), because of reduced crowding of people and dark environments.

Public transport (PT) modes, whether urban or regional, suffer more than private transport modes of this criticality. This is because, on the one hand, in collective transport services the individual is forced to come into contact with strangers, that is, other users of the transport system, while on the other, the characteristics of discontinuity in space and time of these services force the individual to access/egress to/ from terminals, to wait in public places, and to make transfers. Consider also that moving, waiting, and transferring times can be perceived longer depending on the perceived level of safety and security $[4,5]$.

Many authors have pointed out that feelings of safety and security are travelers' primary needs $[6-8]$ and are among 
the main factors affecting customer satisfaction or travelers' perceived quality of PT services [9-12].

In this context, terminals become central and not negligible planning elements if they are intended to improve the overall attractiveness of a collective transport mode.

Many studies in the social sciences have highlighted the existence of a gap between actual and perceived safety and security, and that it is the perceived one that most conditions human behavior. Consider, for instance, the fear of some people of taking an airplane, although, as shown by the statistics, it is actually much safer than traveling by car. In a terminal, the existing gap is mainly attributable to two macrocategories of factors [13]: external environmental factors and individual subjective factors. The former refer to the presence of control and alerts (e.g., security personnel and signage), the level of maintenance and cleanliness, the elements of the built environment (e.g., commercial activities and artificial lighting), and the other external conditions varying with the time of day (e.g., natural lighting and crowding). The latter, instead, refer to the socioeconomic characteristics (e.g., gender, age, and personal), the travel habits (e.g., occasional/systematic traveler and car/public transport user), and the personal attitudes (e.g., self-confident individual and pessimistic person).

The multiplicity and wide spectrum of the factors mentioned above do not suggest taking for granted that an intervention, such as the installation of a video surveillance system, is able to improve the overall sense of safety and security of travelers, since there may be elements of the external environment that could inhibit its effectiveness and, on the other hand, there may be individual subjective factors that could amplify or reduce the perceived intensity of the improvement, i.e., heterogeneous effects.

In this paper, a methodology based on behavioral models is proposed to assess the determinants of travelers' perceived safety and security in the railway stations, although easily generalizable to terminals of other transport systems (e.g., airports and metro stations), with the ultimate goal of identifying the most appropriate and effective interventions to meet travelers' needs and to maximize their satisfaction.

The paper is structured as follows: in Section 2, a state of the art on safety and security perception investigation approaches is provided, outlining the most used data collection techniques and the most advanced behavioral models adopted; Section 3 provides full details on the research method and materials used in this paper for the survey administration and the model estimation; in Section 4, the results of the research are reported and the key findings are discussed; finally, Section 5 summarizes the highlights and conclusions.

\section{Literature Review}

Only a few studies in the literature have focused on evaluating travelers' risk perception of safety-related and security-related issues. On the one hand, some authors have used qualitative surveys to investigate which factors may affect travelers' perceptions [14-17]. However, these studies are limited to a descriptive statistical analysis of the data collected through a survey and/or to a mere correlation analysis among the study variables. On the other hand, very few researchers have developed models to quantitatively assess the weight of each factor. In detail, [18] estimated ordinary least squares regression models to evaluate gender differences in perceptions of train transit safety, focusing on control measures, such as presence of security personnel and security cameras, and on individual characteristics, such as age, gender, ethnicity, disability, and income. Instead, [19] used multiple linear regression to show the relationship between travelers' perception with layout and design of the railway stations, lighting, and passengers' behavior. Furthermore, [4] has estimated more advanced models that allow overcoming the linearity hypotheses, i.e., Logit ordinal regression models, to investigate perceived safety and crime perceptions of public transport users, considering bus stop design, real-time information services, previous experiences of victimization, travelers' sociodemographic characteristics, and travel habits. Finally, [13] has estimated both Logit and Probit specifications of ordered choice models to assess travelers' safety and security perception in railway stations, by introducing in the analysis, in addition to the relevant elements of the build environment, the socioeconomic characteristics and travel behaviors of the individual, also latent personal attitudes such as sense of insecurity and anxiety, pleasure of walking and being in contact with strangers, and many more. The aforementioned studies are mainly based on the administration of questionnaires with closed-ended questions designed on Likert scales, aimed at capturing the opinions and intentions of respondents through their degree of agreement regarding certain statements. Usually, the approach is to compare the stated individual evaluations of specific factors to the stated evaluation of the overall perceived safety and security, considering at the same time the characteristics of the interviewees and the information about the trip they are making. For this reason, data collection strategies mainly involve Revealed Preference/Stated Intention (RP/SI) surveys. For example, respondents may be asked how much they agree from 1 to 5 (where 1 represents "strongly disagree," 2 represents "disagree," 3 "neutral," 4 "agree" and 5 "strongly agree") with the following statements: "a theft is likely to happen in this station," "the presence of other people in the station makes me feel more secure," or "the signage of this station is effective for my safety," and so on.

Instead, for this research, an experimental design for a Stated Preference (SP) survey is conducted, which allows comparing two unlabeled alternatives between them, where a series of key variables that influence the traveler's perception are varied. This method allows quantifying the importance that different users give to the different variables of the study. Moreover, to facilitate the work of the respondent, these variables, instead of being presented in written or numerical form, are represented graphically through edited photos. This technique has the advantage of considering a greater number of variables, reducing the mental effort of the respondent. The only drawback is that since the variables are not labeled, it is likely that individuals ignore some of them, and therefore estimated models may 
have statistically insignificant or incorrectly signed variables. In such cases, the perception of certain variables depends on the perceptions of each user. Several authors have already successfully used a similar approach for evaluating locational preferences of new residents [20], for measuring qualitative attributes of public spaces [21], and for assessing perception of safety in neighborhoods [22].

\section{Methodology}

The research involved the following three main stages:

(i) Identification of key variables, by means of a series of focus groups

(ii) Data collection, through the administration of a SP survey

(iii) Model specification and estimation

Each stage of the methodology is discussed in detail in the following paragraphs.

3.1. Identification of Key Variables (Focus Groups). A series of focus groups with selected travelers, station operators, and management staff of the national infrastructure manager (i.e., Rete Ferroviaria Italiana, RFI) allowed the identification of key elements that should be included in the research. This was achieved using qualitative technique to get preliminary insights from different population segments and stakeholders around a specific topic (e.g., risk of harassment, quality of signage, lighting, crowding, and presence of security personnel). In practice, it consists of an open discussion among 8-10 individuals moderated by an expert, which could also improve awareness and perceptions of key variables [23].

The open discussions within the focus groups mainly concerned two sets of questions, one about actual safety and security and the other on perceived safety and security, such as the following:

(i) What are the determinants affecting security and safety in a station? What strategies, actions, systems, and devices can be implemented to improve the safety and security conditions in a station? Are there any factors that depend on the size of the station, the location, the time-of-day, and the level of crowding?

(ii) How differently may people perceive the measures for safety and security in the station (e.g. signage, surveillance cameras, etc.)? What socioeconomic characteristics and personal attitudes could somehow alter the perception of travelers (e.g. age, gender, education, etc.), and therefore create a gap between actual and perceived safety and security?

The information obtained from the observation during the discussions of the reactions of the participants in the focus group series to the questions and inputs provided by the moderator, in addition to the answers and testimonies of real experiences and stated behaviors, represented a knowledge base for identifying the key variables to investigate and control and for designing the experiments of the survey. This stage made it possible to establish that the elements that could most impact travelers' actual and perceived risk of safety-related and security-related issues concern the following:

(i) External environmental factors, such as presence of security personnel, greenery, road crossings to access the station, surveillance cameras, intermodal infrastructure, commercial activities, artificial lighting, tactile paths and signage, level of crowding, decorum, and maintenance

(ii) Individual subjective factors, such as gender, age, education, income, occupation, car/motorbike ownership, and car/motorbike/train/bus frequency of use

3.2. Data Collection (Stated Preference Survey). The data collection stage was performed through a face-to-face and paper-and-pencil SP survey. The design of the experiments and questionnaires was facilitated by a previous RP/SP survey carried out in the same station in July 2019. On that occasion, a pilot study helped to identify the items of the questionnaire (drawn on Likert scales) that allowed travelers to express their opinions regarding the effectiveness of different security devices and safety measures and about the perceived risk of occurrence of unpleasant events. Based on that experiment, the SP survey described in the present study focused the investigation only on those factors that most affected the perceived safety and security. In detail, the SP survey consisted of two parts:

(i) Forms with graphic representations of station scenarios, by means of which the interviewees were subjected to experiments

(ii) Questionnaire for collecting interviewees' personal information such as socioeconomic attributes and travel behavior characteristics

In an experiment, the interviewee is asked to compare and evaluate a pair of figures (i.e., two scenarios) of the station and then to choose which of the two he feels more confident in, in terms of safety and security (see Figure 1). The graphic representations were based on real photographs of the station, properly edited to eliminate any element that could create biases and noise (e.g., a cloudy sky), subsequently processed with the addition by layers of the key variables that emerged from the focus groups. The processed photos were also accompanied by a table listing the attributes that vary between the two scenarios. Scenarios of three different station environments were shown to users: external square with main entrance, lobby with waiting room, and platforms. This method of investigation allows the collection of a great deal of information in a few moments on what catches the attention of the individual and what influences his perception most. Furthermore, in this way, respondents can easily compare the scenarios through very realistic and familiar graphic elaborations compared to their daily experience [22]. 

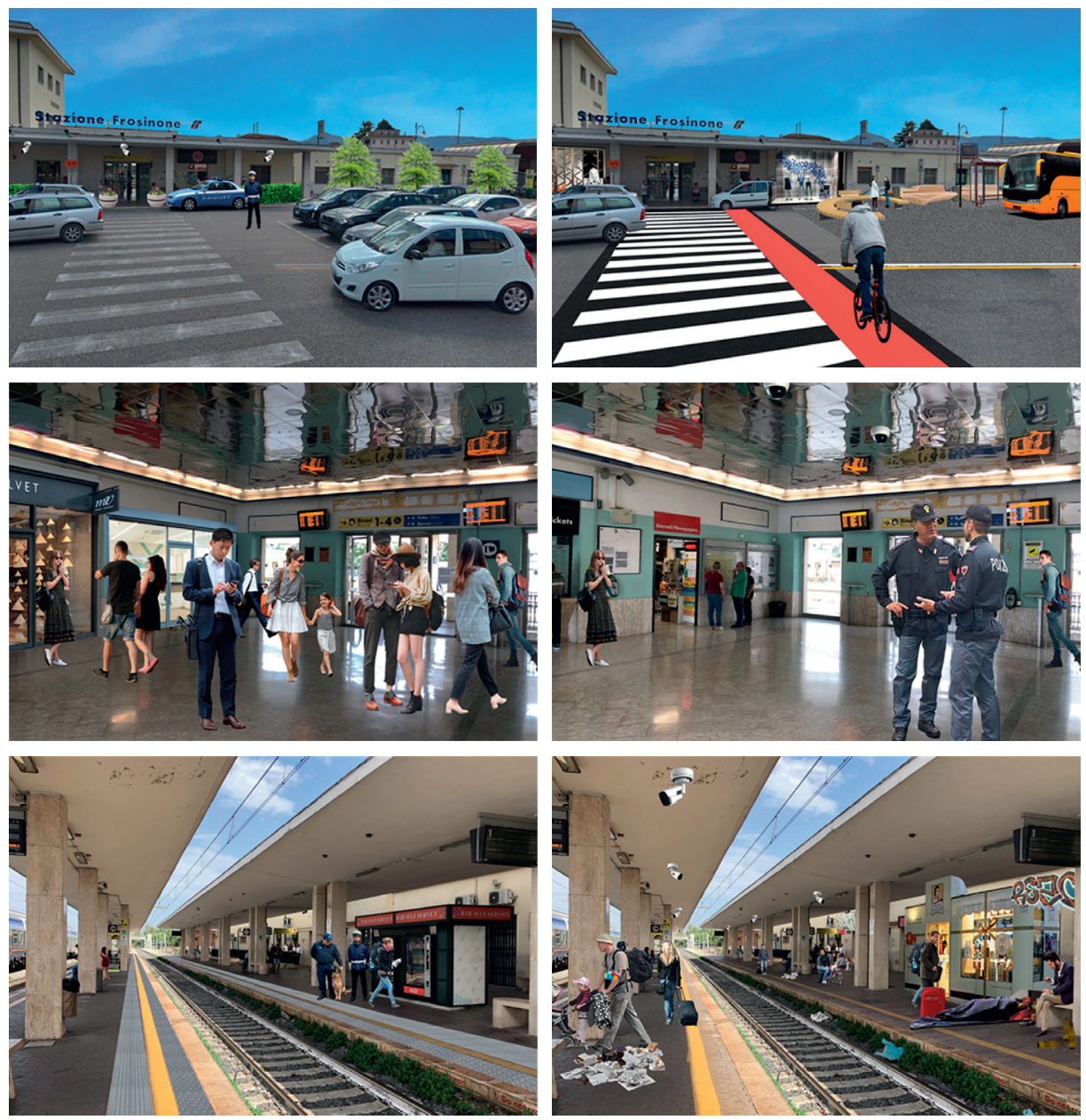

Figure 1: Examples of the figures of the treatments.

All the attributes used for the construction of the scenarios are dummy variable and are summarized in Table 1 with respect to the station environment.

It should be noted that nighttime scenarios were not developed since from the focus groups it immediately emerged that, in such cases, the presence/absence of appropriate artificial lighting would have been an attribute too prominent, which would have dominated the presence or absence of other attributes. In fact, the choice in each treatment would have fallen into the well-lit scenario, and such an investigation would have yielded no information on the weight of the other variables. Artificial lighting in daytime scenarios was instead considered only in the internal premises of the station, i.e., the lobby with waiting room.

The survey was constructed following the optimal or statistically efficient design approach [24, 25], which allows maximizing the information on the parameters of the choice model calibrated on the collected data [26], property that is not guaranteed with the historically most common orthogonal fractional factorial design. In particular, the NGENE software [27] allowed the identification of the most efficient design minimizing the determinant of the inverse of the variance-covariance matrix (i.e., Fisher information matrix) that is known as D-error. This approach enables a reduction in the number of scenarios that need to be shown to an interviewee as well as a reduction in the number of respondents that need to be interviewed.

A total of 24 experiments (i.e., 48 scenarios to be compared in pairs) were created as the result of the combination of the attributes in 3 station environments and 2 blocks consisting of 4 treatments each. In fact, in order to reduce the time needed to interview an individual, only one block was presented to an interviewee. Blocking activity split the efficient design into smaller designs, ensuring that attribute level balance is satisfied within each block, so that respondents do not just face low or high attribute levels for a given attribute.

3.3. Model Specification and Estimation. This research puts emphases on Binomial Logit (BNL) and Mixed Logit (ML) specifications under the Random Utility Theory [24]. In fact, it can be assumed that individuals have well-defined preferences on each of the proposed scenarios, which can be measured by means of a utility function $U$ of the following form: 
TABLe 1: Design of the scenarios.

\begin{tabular}{|c|c|c|c|}
\hline Attribute/environment & External square with main entrance & Lobby with waiting room & Platforms \\
\hline Greenery & $\mathrm{X}$ & & \\
\hline Road crossings & $\mathrm{X}$ & & \\
\hline Intermodal infrastructure & $\mathrm{X}$ & & \\
\hline Security personnel & $\mathrm{X}$ & $\mathrm{X}$ & $\mathrm{X}$ \\
\hline Surveillance cameras & $\mathrm{X}$ & $\mathrm{X}$ & $\mathrm{X}$ \\
\hline Commercial activities & $\mathrm{X}$ & $\mathrm{X}$ & $\mathrm{X}$ \\
\hline Artificial lighting & & $\mathrm{X}$ & \\
\hline Crowding & & $\mathrm{X}$ & $\mathrm{X}$ \\
\hline Tactile path and signage & & & $\mathrm{X}$ \\
\hline Decorum and maintenance & & & $\mathrm{X}$ \\
\hline
\end{tabular}

$$
U_{i}^{j}=\beta \cdot x_{i}^{j}+\varepsilon_{i}^{j}=V_{i}^{j}+\varepsilon_{i}^{j},
$$

where the subscript $i$ represents the $i$-th respondent and the superscript $j$ represents the $j$-th scenario contained in a treatment. Moreover, $x_{i}^{j}$ are level-of-service attributes of the scenario $j$ and any interactions with the characteristics of the respondent $i, \beta$ are parameters associated with the attributes $x_{i}^{j}$, and $\varepsilon_{i}^{j}$ are random residuals. In this framework, the probability of a specific respondent choosing scenario $k$ (as safer than scenario $j$ ) is equal to the probability that the difference in the unobserved components of utility of scenario $j$ compared to $k$ is less than (or equal to) the difference in the observed components of utility of scenario $k$ compared to $j$, for each of the alternative scenarios present in the choice set $J$ (in this case $J=\{1,2\}$ because a treatment is made up of a pair of scenarios). Therefore, in notation,

$$
\begin{aligned}
\operatorname{Prob}^{k} & =\operatorname{Prob}\left[\left(U^{k} \geq U^{j}\right) \forall j \in J ; j \neq k\right] \\
& =\operatorname{Prob}\left[\left(\varepsilon^{j}-\varepsilon^{k}\right) \leq\left(V^{k}-V^{j}\right) \forall j \in J ; k \neq j\right] .
\end{aligned}
$$

In detail, the systematic utility function $V$ consists of the following parameters and attributes of the scenario $j$ (except for any possible interactions with the socioeconomic characteristics or travel behaviors of the respondent $i$ ):

$$
\begin{aligned}
& V_{i}^{j}= \beta_{\mathrm{SC}} \cdot \text { SurveillanceCameras }^{j}+\beta_{\mathrm{SP}} \cdot \text { SecurityPersonnel }^{j} \\
&+\beta_{\mathrm{CA}} \cdot \text { CommercialActivities }^{j}+\beta_{\mathrm{RC}} \cdot \text { RoadCrossings }^{j} \\
&+\beta_{\mathrm{S}} \cdot \text { Signage }^{j}+\beta_{\mathrm{G}} \cdot \text { Greenery }^{j} \\
&+\beta_{\mathrm{IF}} \cdot \text { IntermodalInfrastructure }^{j} \\
&+\beta_{\mathrm{AL}} \cdot \text { ArtificialLighting }^{j}+\beta_{\mathrm{C}} \cdot \text { Crowding }^{j} \\
&+\beta_{\mathrm{DM}} \cdot \text { DecorumMaintenance } \\
&
\end{aligned}
$$

Since the parameters are generic over the scenarios, and there are no alternative-specific constants, then the alternative scenarios are so-called unlabeled.

In this context, the BNL models allowed highlighting easily which factors most affect safety and security perception of all travelers (of the overall sample) and any interactions with socioeconomic attributes, while the ML models made it possible to verify the existence of heterogeneity in travelers' choice behavior, i.e., differences in the preferences that may occur among different categories of respondents. The identification of travelers' random taste variation was possible by allowing the parameters to be random.

The aforementioned models were estimated with the NLOGIT software [28], using the Maximum Likelihood Estimation (MLE) method for the BNL specifications and the Maximum Simulated Likelihood Estimation (MSLE) method for the ML specifications.

In fact, for the BNL it can be demonstrated that the probability that respondent $i$ chooses alternative $k$ can be calculated with the following expression [29]:

$$
P_{i}^{k}=\frac{e^{V_{i}^{k}}}{\sum_{j} e^{V_{i}^{j}}}, \quad \forall j \in J ; k \neq j .
$$

Given that these probabilities take a closed form, the traditional MLE method can be applied. The probability of respondent $i$ choosing the scenario that he was actually observed to choose can be expressed as

$$
\prod_{j}\left(P_{i}^{j}\right)^{y_{i}^{j}},
$$

where $y_{i}^{j}$ is equal to 1 if respondent $i$ chose scenario $j$; otherwise $y_{i}^{j}$ is equal to 0 . Under the assumptions that each choice of the respondent is independent of that of other respondents, the probability of each respondent in the sample choosing the scenario that he was observed to choose is [29]

$$
L(\beta)=\prod_{i} \prod_{j}\left(P_{i}^{j}\right)^{y_{i}^{j}}
$$

where $\beta$ is the vector of the parameters associated with the attributes of the model. By applying the logarithm to the latter expression, a simpler formulation is obtained, although it is guaranteed that the maximum value of the log of the probability occurs at the same point as the original probability function. Thus, the log-likelihood function is

$$
\operatorname{LL}(\beta)=\sum_{i} \sum_{j} y_{i}^{j} \ln \left(P_{i}^{j}\right) .
$$

In practice, the MLE method finds the set of parameters $\beta$ (the estimators) that maximizes the log-likelihood function, i.e., the probability of having predictions corresponding to the observed data. 
On the other hand, in the case of ML, the probability that respondent $i$ chooses scenario $k$ cannot be expressed in a closed form, but as [29]

$$
P_{i}^{j}=\int L_{i}^{j}(\beta) f(\beta \mid \theta) d \beta
$$

where

$$
L_{i}^{k}(\beta)=\frac{e^{\beta^{\prime} x_{i}^{k}}}{\sum_{j} e^{\beta^{\prime} x_{i}^{j}}}, \quad \forall j \in J ; k \neq j,
$$

since the (random) parameters $\beta$ depend on the characteristics of the respondent $i$ that are distributed generically with density $f(\beta \mid \theta)$ and whose parameters $\theta$ need to be estimated. The probabilities are approximated through simulation for any given value of $\theta$, drawing a value of $\beta$ from $f(\beta \mid \theta)$, labeling it as $\beta^{r}$, and calculating the Logit formula $L_{i}^{j}\left(\beta^{r}\right)$. The results are averaged to obtain the simulated probability:

$$
\check{P}_{i}^{j}=\frac{1}{R} \sum_{r} L_{i}^{j}\left(\beta^{r}\right),
$$

where $R$ is the number of draws. In detail, the simulation method used in this study is that of Halton sequences, with a number of 200 draws. Finally, the simulated log-likelihood function is created from the simulated probabilities:

$$
\operatorname{SLL}(\theta)=\sum_{i} \sum_{j} y_{i}^{j} \ln \left(\check{P}_{i}^{j}\right),
$$

where $y_{i}^{j}$ is equal to 1 if respondent $i$ chose scenario $j$; otherwise $y_{i}^{j}$ is equal to 0 . Similarly to what was shown before, the MSLE method finds the set of parameters $\theta$ that maximizes the simulated log-likelihood function.

\section{Results and Discussion}

4.1. Sample Description. A total of more than 350 travelers were interviewed in the rail station of Frosinone; however, the sample taken into consideration is made up of 302 respondents, i.e., those who successfully completed 1 block consisting of 4 treatments. Hence, the overall number of observations is 1,208 .

Respondents were randomly approached in different points of the three station environments investigated. For instance, travelers were interviewed in the external square, at the main entrance, in the atrium of the station, near the ticket office, in the waiting room, near the commercial activities (such as shops, cafes, and newsstands), at the access stairs to the underpass, and at the waiting areas of the several platforms.

The interviews were collected from the 9th to the 22nd of December 2019 (excluding Sundays) during extended morning periods (i.e., 6:30 a.m. and 12:00 a.m.), including the early hours and the peak period, in order to assess whether the degree of crowding of the station and the faint light of early morning can affect the perceived level of safety and security. Sundays and other holidays were excluded from the sampling days since the rail service is very limited on those days. In fact, the rail service in the Frosinone station is designed particularly for students and commuters directed to Rome (at 1 hour and 15 minutes) and to the University of Cassino (at 35 minutes).

The sample distribution has been validated against the population of travelers of the station of Frosinone, made available by the national infrastructure manager through its research laboratory, i.e., "Osservatorio di Mercato-RFI."

It can be observed (Table 2) that, with respect to the socioeconomic characteristics, $48.7 \%$ of the interviewees are women; $82.5 \%$ are under 45 years old; $51.3 \%$ have a highschool diploma; and $44.0 \%$ have a university degree. The fact that $57.3 \%$ of the interviewees declare no income reflects the big percentage of students in the sample (47.0\%).

As far as travel behavior is concerned, it should be noted that $76.2 \%$ of respondents own a car, but only $60.6 \%$ use it with a high frequency and mainly to reach the train station (park-and-ride). In the sample, there are also a nonnegligible percentage of occasional users, which ensures that no bias due to experience can influence model estimation, e.g., amplifying or reducing travelers' risk perception.

4.2. Estimated Behavioral Models. The results of the BNL estimated models are reported in Table 3, whereas comparisons between BNL and ML estimated models are shown in Table 4.

Three BNL model specifications are proposed, using all sample observations.

The first model specification (MODEL 1) includes all the attributes used for the construction of the scenarios. All the estimated coefficients are expected to be positive since each design element should increase the level of safety and security perceived by travelers. This occurs for all variables except for "tactile path and signage," which is inconsistent in sign with what has been hypothesized. Additionally, two other variables are not statistically significant, i.e., "commercial activities" and "artificial lighting," which have a $t$ ratio of 1.21 and 0.73 , respectively. Probably these results can be explained by assuming that people do not know or are unaware of the existence of "tactile path and signage" and, since it has not been maintained for years, it is an aspect that they totally ignore by shifting their attention to the other attributes presented. With regard to "commercial activities," the sign of the parameter is positive, which means that the attribute increases the utility, even if on average from a statistical point of view it is irrelevant. Nonetheless, although this variable initially appears to be irrelevant, it actually acquires relevance to some travelers, as demonstrated later in the ML models. It will be seen how something similar also happens to the variable "artificial lighting," albeit in an attenuated way.

Now focusing on the values assumed by the parameters of the variables, in general (in all the models presented), the most important attributes of a railway station for a traveler are, in order of preference expressed by MODEL 1, "Road crossings" (1.12) and "Decorum and maintenance" (1.11) as regards safety-related issues and "Security personnel" (0.89) with regard to security-related issues. These weight 
TABLE 2: Socioeconomic attributes and travel behavior characteristics of the sample.

\begin{tabular}{|c|c|c|c|c|c|}
\hline \multicolumn{3}{|c|}{ Socioeconomic attributes } & \multicolumn{3}{|c|}{ Travel behavior characteristics } \\
\hline \multirow{2}{*}{ Gender } & Female & $48.7 \%$ & \multirow{2}{*}{ Car ownership } & Yes & $76.2 \%$ \\
\hline & Male & $51.3 \%$ & & No & $23.8 \%$ \\
\hline \multirow{6}{*}{ Age } & $<26$ & $46.4 \%$ & \multirow{2}{*}{ Motorbike ownership } & Yes & $9.6 \%$ \\
\hline & $26-35$ & $22.2 \%$ & & No & $90.4 \%$ \\
\hline & $36-45$ & $13.9 \%$ & \multirow{4}{*}{ Car frequency of use (days/week) } & $-6+$ & $60.6 \%$ \\
\hline & $46-55$ & $10.6 \%$ & & $3-5$ & $21.2 \%$ \\
\hline & $56-65$ & $5.0 \%$ & & $0-2$ & $18.2 \%$ \\
\hline & $>65$ & $2.0 \%$ & & $-6+$ & $1.7 \%$ \\
\hline \multirow{5}{*}{ Highest education } & None & $0.7 \%$ & \multirow[t]{2}{*}{ Motorbike frequency of use (days/week) } & $3-5$ & $3.0 \%$ \\
\hline & Elementary school & $0.0 \%$ & & $0-2$ & $95.4 \%$ \\
\hline & Middle school & $4.0 \%$ & \multirow{3}{*}{ Train frequency of use (days/week) } & $-6+$ & $48.3 \%$ \\
\hline & High school & $51.3 \%$ & & $3-5$ & $28.5 \%$ \\
\hline & University & $44.0 \%$ & & $0-2$ & $23.2 \%$ \\
\hline \multirow{3}{*}{ Occupation } & Employed & $38.7 \%$ & \multirow{8}{*}{ Bus frequency of use (days/week) } & $-6+$ & $35.4 \%$ \\
\hline & Student & $47.0 \%$ & & $3-5$ & $17.9 \%$ \\
\hline & Other & $14.2 \%$ & & $0-2$ & $46.7 \%$ \\
\hline \multirow{5}{*}{ Monthly income } & None & $57.3 \%$ & & & \\
\hline & $<901 €$ & $3.0 \%$ & & & \\
\hline & $901-1500 €$ & $16.2 \%$ & & & \\
\hline & $1501-2500 €$ & $18.9 \%$ & & & \\
\hline & $>2500 €$ & $4.6 \%$ & & & \\
\hline
\end{tabular}

TABle 3: Binomial Logit estimated models.

\begin{tabular}{|c|c|c|c|c|c|c|}
\hline & \multicolumn{2}{|c|}{ MODEL 1} & \multicolumn{2}{|c|}{ MODEL 2} & \multicolumn{2}{|c|}{ MODEL 3} \\
\hline Specification & \multicolumn{2}{|c|}{ Binomial Logit } & \multicolumn{2}{|c|}{ Binomial Logit } & \multicolumn{2}{|c|}{ Binomial Logit } \\
\hline Description & \multicolumn{2}{|c|}{ All attributes } & \multicolumn{2}{|c|}{$\begin{array}{l}\text { Consistent attributes in } \\
\text { sign only and } \\
\text { interactions with } \\
\text { socioeconomic (SE) } \\
\text { characteristics }\end{array}$} & \multicolumn{2}{|c|}{$\begin{array}{c}\text { Consistent attributes in } \\
\text { sign only and } \\
\text { interactions with SE } \\
\text { characteristics and } \\
\text { travel habits }\end{array}$} \\
\hline \#observations & \multicolumn{2}{|c|}{1208} & \multicolumn{2}{|c|}{1208} & \multicolumn{2}{|c|}{1208} \\
\hline Log-likelihood function (constants) & \multicolumn{2}{|c|}{-835.5} & \multicolumn{2}{|c|}{-835.5} & \multicolumn{2}{|c|}{-835.5} \\
\hline Log-likelihood function (fitted) & \multicolumn{2}{|c|}{-648.1} & \multicolumn{2}{|c|}{-636.6} & \multicolumn{2}{|c|}{-627.9} \\
\hline Pseudo-R2 & \multicolumn{2}{|c|}{0.224} & \multicolumn{2}{|c|}{0.238} & \multicolumn{2}{|c|}{0.249} \\
\hline Akaike information criterion & \multicolumn{2}{|c|}{1316.3} & \multicolumn{2}{|c|}{1297.2} & \multicolumn{2}{|c|}{1285.9} \\
\hline Variable & Coeff. & $t$-ratio & Coeff. & $t$-ratio & Coeff. & $t$-ratio \\
\hline Surveillance cameras & $0.46^{* * *}$ & 6.25 & $0.47^{* * *}$ & 6.35 & $0.45^{* * *}$ & 6.01 \\
\hline Security personnel & $0.89^{* * *}$ & 11.81 & $1.07^{* * *}$ & 11.09 & $1.10^{* * *}$ & 11.22 \\
\hline Security personnel, ${ }^{*}$ employed & & & $-0.45^{* * *}$ & -3.22 & $-0.47^{* * *}$ & -3.34 \\
\hline Commercial activities & 0.08 & 1.21 & 0.08 & 1.10 & 0.08 & 1.18 \\
\hline Road crossings & $1.12^{* * *}$ & 6.49 & $1.05^{* * *}$ & 8.56 & $0.78^{* * *}$ & 4.37 \\
\hline Road crossings, ${ }^{*}$ freq. car high & & & & & $0.49^{* *}$ & 2.09 \\
\hline Tactile path and signage & -0.09 & -0.72 & & & & \\
\hline Greenery & $0.25^{* *}$ & 2.18 & $0.54^{* * *}$ & 3.15 & $0.56^{* * *}$ & 3.21 \\
\hline Greenery, ${ }^{*}$ female & & & $-0.53^{* *}$ & -2.29 & $-0.54^{* *}$ & -2.32 \\
\hline Intermodal infrastructure & $0.45^{* * *}$ & 3.69 & $0.46^{* * *}$ & 3.79 & $0.27^{*}$ & 1.84 \\
\hline Intermodal infrastructure, ${ }^{*}$ freq. PT high & & & & & $0.67^{* * *}$ & 2.70 \\
\hline Artificial lighting & 0.09 & 0.73 & 0.09 & 0.74 & 0.09 & 0.74 \\
\hline Crowding & $0.34^{* * *}$ & 3.81 & 0.07 & 0.60 & 0.10 & 0.84 \\
\hline Crowding, ${ }^{*}$ female & & & $0.51^{* * *}$ & 2.94 & $0.46^{* * *}$ & 2.62 \\
\hline Decorum and maintenance & $1.11^{* * *}$ & 8.88 & $1.12^{* * *}$ & 9.00 & $1.00^{* * *}$ & 7.36 \\
\hline Decorum and maintenance, ${ }^{*}$ freq. rail low & & & & & $0.72^{* *}$ & 2.16 \\
\hline
\end{tabular}

The symbols ${ }^{* * *},{ }^{* *}$, and ${ }^{*}$ indicate significance at $1 \%, 5 \%$, and $10 \%$ level.

approximately three/four times the value of the parameters of "Surveillance cameras" (0.46), "Intermodal infrastructure" (0.45), "Crowding" (0.34), and "Greenery" (0.25).

In a second model (MODEL 2), insignificant variables were excluded from the model specifications, whereas some interactions with socioeconomic attributes were included. Some of these interactions have proven to be significant, for example, "security personnel" that seems to be significant only for unemployed people or "crowding" that seem to be significant only for female gender. 
TABLe 4: Comparison between Binomial Logit and Mixed Logit estimated models.

\begin{tabular}{|c|c|c|c|c|c|c|c|c|c|c|c|c|}
\hline & \multicolumn{2}{|c|}{ MODEL 1} & \multicolumn{4}{|c|}{ MODEL 4} & \multicolumn{2}{|c|}{ MODEL 3} & \multicolumn{4}{|c|}{ MODEL 5} \\
\hline Specification & \multicolumn{2}{|c|}{ Binomial Logit } & \multicolumn{4}{|c|}{ Mixed Logit } & \multicolumn{2}{|c|}{ Binomial Logit } & \multicolumn{4}{|c|}{ Mixed Logit } \\
\hline Description & \multicolumn{2}{|c|}{ All attributes } & All a & $\begin{array}{r}\text { ttribute } \\
\text { para }\end{array}$ & $\begin{array}{l}\text { with ran } \\
\text { meters }\end{array}$ & dom & \multicolumn{2}{|c|}{$\begin{array}{l}\text { Consistent } \\
\text { attributes in sign } \\
\text { only and } \\
\text { interactions with } \\
\text { SE } \\
\text { characteristics } \\
\text { and travel habits }\end{array}$} & \multicolumn{4}{|c|}{$\begin{array}{l}\text { Consistent attributes in sign only } \\
\text { with random parameters and } \\
\text { interactions with SE characteristics } \\
\text { and travel habits }\end{array}$} \\
\hline \#observations & \multicolumn{2}{|c|}{1208} & \multicolumn{4}{|c|}{1208} & \multicolumn{2}{|c|}{1208} & \multicolumn{4}{|c|}{1208} \\
\hline $\begin{array}{l}\text { Log-likelihood function } \\
\text { (constants) }\end{array}$ & \multicolumn{2}{|c|}{-835.5} & \multicolumn{4}{|c|}{-835.5} & \multicolumn{2}{|c|}{-835.5} & \multicolumn{4}{|c|}{-835.5} \\
\hline $\begin{array}{l}\text { Log-likelihood function } \\
\text { (fitted) }\end{array}$ & \multicolumn{2}{|c|}{-648.1} & \multicolumn{4}{|c|}{-574.5} & \multicolumn{2}{|c|}{-627.9} & \multicolumn{4}{|c|}{-562.3} \\
\hline Pseudo-R2 & \multirow{2}{*}{\multicolumn{2}{|c|}{$\begin{array}{c}0.224 \\
1316.3\end{array}$}} & \multirow{2}{*}{\multicolumn{4}{|c|}{$\begin{array}{c}0.314 \\
1189.1\end{array}$}} & \multirow{2}{*}{\multicolumn{2}{|c|}{$\begin{array}{c}0.249 \\
1285.9 \\
\end{array}$}} & \multirow{2}{*}{\multicolumn{4}{|c|}{$\begin{array}{c}0.328 \\
1162.6\end{array}$}} \\
\hline Akaike information criterion & & & & & & & & & & & & \\
\hline Variable & Coeff. & $t$-ratio & Coeff. & $t$-ratio & Std. dev. & $t$-ratio & Coeff. & $t$-ratio & Coeff. & $t$-ratio & Std. dev. & t-ratio \\
\hline Surveillance cameras & $0.46^{* * *}$ & 6.25 & $1.21^{* * *}$ & 3.77 & 0.94 & 0.80 & $0.45^{* * *}$ & 6.01 & $0.90^{* * *}$ & 5.29 & $1.84^{* *}$ & 3.84 \\
\hline Security personnel & $0.89^{* * *}$ & 11.81 & $2.58^{* * *}$ & 4.10 & 1.78 & 1.40 & $1.10^{* * *}$ & 11.22 & $2.36^{* * *}$ & 6.76 & $3.88^{* * *}$ & 7.73 \\
\hline $\begin{array}{l}\text { Security personnel, } \\
\text { *employed }\end{array}$ & & & & & & & $-0.47^{* * *}$ & -3.34 & $-1.12^{* * *}$ & -2.84 & & \\
\hline Commercial activities & 0.08 & 1.21 & $0.29^{*}$ & 1.70 & $2.36^{* *}$ & 2.57 & 0.08 & 1.18 & 0.20 & 1.60 & & \\
\hline Road crossings & $1.12^{* * *}$ & 6.49 & $3.27^{* * *}$ & 3.42 & 1.35 & 0.92 & $0.78^{* * *}$ & 4.37 & $1.66^{* * *}$ & 3.42 & $2.78^{* * *}$ & 3.44 \\
\hline $\begin{array}{l}\text { Road crossings, * freq. car } \\
\text { high }\end{array}$ & & & & & & & $0.49^{* *}$ & 2.09 & 0.95 & 1.61 & & \\
\hline Tactile path and signage & -0.09 & -0.72 & -0.01 & -0.03 & $5.01^{* * *}$ & 3.99 & & & & & & \\
\hline Greenery & $0.25^{* *}$ & 2.18 & $0.79^{* *}$ & 2.36 & 0.78 & 0.65 & $0.56^{* * *}$ & 3.21 & $1.16^{* * *}$ & 4.04 & & \\
\hline Greenery, ${ }^{*}$ female & & & & & & & $-0.54^{* *}$ & -2.32 & $-1.14^{* * *}$ & -3.04 & & \\
\hline Intermodal infrastructure & $0.45^{* * *}$ & 3.69 & $1.34^{* *}$ & 2.56 & $5.43^{* * *}$ & 3.66 & $0.27^{*}$ & 1.84 & 0.39 & 1.03 & & \\
\hline $\begin{array}{l}\text { Intermodal infrastructure, } \\
{ }^{*} \text { freq. PT high }\end{array}$ & & & & & & & $0.67^{* * *}$ & 2.70 & $1.72^{* *}$ & 2.52 & & \\
\hline Artificial lighting & 0.09 & 0.73 & 0.26 & 1.08 & $1.46^{*}$ & 1.78 & 0.09 & 0.74 & 0.19 & 1.07 & & \\
\hline Crowding & $0.34^{* * *}$ & 3.81 & $0.78^{* *}$ & 2.17 & $4.09^{* * *}$ & 3.20 & 0.10 & 0.84 & 0.04 & 0.11 & & \\
\hline Crowding, ${ }^{*}$ female & & & & & & & $0.46^{* * *}$ & 2.62 & $0.82^{*}$ & 1.73 & & \\
\hline Decorum and maintenance & $1.11^{* * *}$ & 8.88 & $3.44^{* * *}$ & 3.72 & $4.95^{* *}$ & 2.44 & $1.00^{* * *}$ & 7.36 & $2.26^{* * *}$ & 4.85 & $4.33^{* * *}$ & 5.74 \\
\hline $\begin{array}{l}\text { Decorum and maintenance, } \\
* \text { freq. rail low }\end{array}$ & & & & & & & $0.72^{* *}$ & 2.16 & $1.72^{* *}$ & 2.13 & & \\
\hline
\end{tabular}

The symbols ${ }^{* * *},{ }^{* *}$, and ${ }^{*}$ indicate significance at $1 \%, 5 \%$, and $10 \%$ level.

In MODEL 3, in addition to the socioeconomic attributes, also travel behavior characteristics were considered. Here emerges that segmenting users by frequency of use of car, public transport, and rail increases the robustness of the model (see the variations in the goodness-of-fit statistics, i.e., log-likelihood and pseudo-R2, shown in Table 3). For example, the project element "road crossings" seems to be significant and to be of greater importance for users who use the car very frequently. This can be explained by the fact that car parks are separated from the station by a wide and busy road, and therefore this is perceived to be very dangerous to cross. The arrangement of the road crossing in the figures presented to travelers is highly appreciated by them. More obvious is the fact that the "intermodal infrastructure" variable is significant mainly for users who use public transport very frequently. Furthermore, "decorum and maintenance" seems to be more relevant for nonhabitual users of the station. If those who go to the station every day for commuting (e.g., home-work or home-study trips) are more indifferent to the state of conservation of the premises and external environments of the station, perhaps this is because they have become accustomed to it.

Two ML model specifications are proposed, using all sample observations, and are compared with their respective BNL versions with nonrandom parameters. The distribution function used in both ML models is uniform, given the nature of the attributes which are dummy variables. Indeed, in such cases, the uniform distribution is sensible to verify the consistency of the signs of the parameters [30], because it does not impose any a priori condition on the sign of the parameter (which could have been done using a lognormal distribution). This choice, as will be seen in the proposed models, arises from the conjecture that the presence of some design elements for some individuals can increase the perceived safety and security, while for others it could decrease it. For example, the need for surveillance cameras and security personnel at the station could have a negative impact, because it might suggest to some travelers that theft, harassment, or aggression is likely to occur in the station environments. The uniform distribution also has the 
advantage of having limited support, which reduces the possibility of unreasonably high or low coefficient values [31]. Furthermore, the observations were treated as panel data, to take into consideration the possible correlation that exists between the responses to the different treatments of the same interviewee.

In detail, starting from MODEL 1 (i.e., the one without any interaction), MODEL 4 was specified by setting on random parameters the coefficients associated with all the variables relating to the design elements. As can be seen from Table 4, the use of random parameters is reasonable only for some variables. In particular, it is widely justifiable for "intermodal infrastructure," "decorum and maintenance," and "crowding," for which both the coefficient (which represents the mean of the distribution) and the standard deviation have significance at least at 5\% level. Moreover, MODEL 4 shows that even if the sign of the variable "tactile path and signage" is not consistent, the standard deviation is very large with respect to the mean parameter. This indicates that the variable is perceived very differently among the people interviewed. It is also important to note that, with this model, the statistical significance of "commercial activities" increases and the standard deviation of the parameter is significant, since, on the one hand, the panel data effect and, on the other, the heterogeneity of the population in the perception of the parameter are considered. Even though these random tastes could not be fully explained, both effects could not be considered with the low complexity of a BNL model. In the case of "artificial lighting," even if the statistical significance increases and the standard deviation has a $t$ ratio of 1.78 (MODEL 4), it is likely that globally this variable is not perceived by users.

Finally, a fifth model (MODEL 5) was specified starting from the most robust BNL estimated models (i.e., MODEL 3). In this case, we present a final version of the specification that does not include random parameters associated with all the variables, but rather only with the variables that demonstrate the existence of differences in preferences between the different categories of respondents. It should be noted that in some cases the interactions lose significance or vice versa; the variables are no longer significant for all travelers, but only for some specific categories, i.e., when a strong interaction has been identified.

\section{Conclusions}

A novel methodology, based on focus group, SP survey, and the estimation of behavioral models, is presented in this paper for assessing determinants of perceived safety and security in railway stations.

Data were collected by means of a face-to-face questionnaire where the interviewers reported the interviewees' stated preference on the base of their feelings and perceptions about some station scenarios, illustrated through forms consisting of a graphic representation of the station. The forms were obtained from real photos, suitably modified to avoid any background noise and biases, in order to show very realistic and familiar graphic elaborations compared to respondents' daily experience. This data collection strategy had the advantage to allow the respondents to quickly compare two unlabeled alternatives with low mental effort, considering a great number of variables that varied from scenario to scenario. In this way, instead of asking respondents their degree of agreement to a certain statement on a scale of 1 to 5 (as is usually done using Likert scales), interviewees were asked to choose which of the two scenarios they felt safer in. With this method, therefore, no opinions and stated intentions have been collected, but rather individuals' choices. On the other hand, a drawback of this methodology is that there could be possible discrepancies between the stated choice and the behavior that the traveler would have. This happens mainly due to the unrealistic presence or absence of some safety and security measures, the lack of information on the scenarios analyzed, and the fatigue of the respondents for completing too many treatments. However, these issues were controlled by presenting scenarios with similar contexts to what travelers experience every day and by exposing each interviewee to only 4 treatments (requiring an overall completion time of 10 minutes).

The estimation of the models was performed using a sample size of 1,208 observations, and two different Logit specifications, i.e., BNL and ML, which involved, respectively, fixed and random parameters. The need of introducing random parameter in the models' specifications derives from the way in which data were collected. In fact, since the variables presented in the forms (e.g. lighting, security personnel, and crowding) were not labeled, respondents could ignore or partially perceive some of them according to their attitudes, tastes, and cognitive capacity. This is proved by the fact that when randomness in parameters is introduced the model estimates improved also for those variables that were not statistically significant or that had with an incorrect sign. As seen by the pseudo-R2, the use of random parameters has proved to be an appropriate choice, leading to the estimation of more robust behavioral models than in the case of fixed parameters.

The statistical explanation of the heterogeneity in user preferences is deferred to future research. Better profiling of travelers could lead to even more robust models but above all it is of utmost importance to implement targeted measures, both infrastructural and organizational, in order to make railway stations a safer place and therefore increase the attractiveness of railway services. The models show that safety and security systems are not equally perceived by all individuals. There are some measures that (at the same cost) could have more impact than others. Therefore, assuming the safety standards are respected, if a railway manager intends to further increase the sense of safety, then the investments should be prioritized according to those variables most perceived by users, such as increasing the presence of "security personnel" and the level of "decorum and maintenance," even before acting on those of lesser impact such as installing additional "surveillance cameras."

Finally, in this research the application to a medium-size railway station was analyzed, but it is quite immediate to think of adopting and applying this methodological approach also to high-speed rail (HSR) stations to better 
address users' needs after the increase of HSR volumes observed after the completion of the network in Italy [32], as well as to other nodes of the public transport networks such as a metro station, a bus stop, and an airport and even to nodes of the road and pedestrian networks, such as an urban intersection or a roundabout, with the aim of improving the feeling of safety and security of users.

\section{Data Availability}

Most datasets used and/or analyzed during the current study are available from the corresponding author upon reasonable request. Restrictions apply to the availability of data that were used under license for the current study, and so they are not publicly available. These data are, however, available from the authors with permission from Ferrovie dello Stato Italiane (Italian Railways Company).

\section{Conflicts of Interest}

The authors declare that they have no conflicts of interest.

\section{References}

[1] C. Alm and E. Lindberg, The Importance of Perceived Risks And Feelings of Unsafety Associated With Travels With Public Transport Modes, Vol. 962, Swedish National Road and Transport Research Institute Report, Linkoping, Sweden, 2004.

[2] A. Backer-Grøndahl, A. Fyhri, P. Ulleberg, and A. H. Amundsen, "Accidents and unpleasant incidents:worry in transport and prediction of travel behavior," Risk Analysis, vol. 29, no. 9, 2009.

[3] R. B. Noland, "Perceived risk and modal choice: risk compensation in transportation systems," Accident Analysis \& Prevention, vol. 27, no. 4, pp. 503-521, 1995.

[4] R. F. Abenoza, V. Ceccato, Y. O. Susilo, and O. Cats, "Individual, travel, and bus stop characteristics influencing travelers' safety perceptions," Transportation Research Record: Journal of the Transportation Research Board, vol. 2672, no. 8, pp. 19-28, 2018.

[5] H. Iseki and B. D. Taylor, "Not all transfers are created equal: towards a framework relating transfer connectivity to travel behaviour," Transport Reviews, vol. 29, no. 6, pp. 777-800, 2009.

[6] J. Allen, J. C. Muñoz, and J. d. D. Ortúzar, “Understanding public transport satisfaction: using Maslow's hierarchy of (transit) needs," Transport Policy, vol. 81, pp. 75-94, 2019.

[7] V. Ceccato, Moving Safely. Crime And Perceived Safety In Stockholm's Subway Stations, Lexington Books, Lanham, MA, USA, 2013.

[8] M. van Hagen and J. Sauren, "Influencing the train experience: using a successful measurement instrument," Transportation Research Procedia, vol. 1, pp. 264-275, 2014.

[9] M. G. Bellizzi, L. F. Eboli, and G. Mazzulla, "Air transport passengers' satisfaction: an ordered logit model," Transportation Research Procedia, vol. 33, pp. 147-154, 2018.

[10] L. Eboli and G. Mazzulla, "Service quality attributes affecting customer satisfaction for bus transit," Journal of Public Transportation, vol. 103 pages, 2007.

[11] M. G. Karlaftis, J. Golias, and E. Papadimitriou, "Transit quality as an integrated traffic management strategy: measuring perceived service," Journal of Public Transportation, vol. 4, no. 1, pp. 27-44, 2001.

[12] W.-T. Lai and C.-F. Chen, "Behavioral intentions of public transit passengers: the roles of service quality, perceived value, satisfaction and involvement," Transport Policy, vol. 18, no. 2, pp. 318-325, 2011.

[13] P. Coppola and F. Silvestri, "Assessing travelers' safety and security perception in railway stations," Case Studies on Transport Policy, vol. 8, no. 4, pp. 1127-1136, 2020.

[14] A. F. Amir and M. N. I. Ismail, "Sustainable Tourist Environment: Perception of international women travelers on safety and security in Kuala Lumpur," Procedia-Social and Behavioral Sciences, vol. 168, pp. 123-133, 2015.

[15] G. Currie, A. Delbosc, and S. Mahmoud, "Perceptions and realities of personal safety on public transport for young people in melbourne," in Proceedings of the 33rd Australasian Transport Research Forum Conference, Canberra, AU, USA, September 2010.

[16] A. Fyhri, T. Hof, Z. Simonova, and M. de Jong, "The influence of perceived safety and security on walking," Perceptions of Risk, vol. 2, pp. 49-70, 2010.

[17] Y. Park and M. Garcia, "Pedestrian safety perception and urban street settings," International Journal of Sustainable Transportation, vol. 14, 2019.

[18] N. Yavuz and E. W. Welch, "Addressing fear of crime in public space: gender differences in reaction to safety measures in train transit," Urban Studies, vol. 47, no. 12, pp. 2491-2515, 2010.

[19] N. Abdul Hamid, P.-L. Tan, M. F. Mohamad Zali, N. U. Rahamat, and N. Abd Aziz, "Safety and security needs of commuter rail services-travellers' perceptions," Journal of the Eastern Asia Society for Transportation Studies, vol. 11, 2015.

[20] I. Torres, M. Greene, and J. D. Ortúzar, "Valuation of housing and neighbourhood attributes for city centre location: a case study in Santiago," Habitat International, vol. 39, pp. 62-74, 2013.

[21] R. Hurtubia, A. Guevara, and P. Donoso, "Using images to measure qualitative attributes of public spaces through SP surveys," Transportation Research Procedia, vol. 11, pp. 460474, 2015.

[22] P. Iglesias, M. Greene, and J. D. Ortúzar, "On the perception of safety in low income neighbourhoods: using digital images in a stated choice experiment. Chapters," in Choice Modelling, S. Hess and A. Daly, Eds., pp. 193-210, Edward Elgar Publishing, Cheltenham, UK, 2013.

[23] E. Papa, P. Coppola, G. Angiello, and G. Carpentieri, "The learning process of accessibility instrument developers: testing the tools in planning practice," Transportation Research Part A Policy and Practice, vol. 104, pp. 108-120, 2013.

[24] D. A. Hensher, J. M. Rose, and W. H. Greene, Applied Choice Analysis. A Primer, Cambridge University Press, Cambridge, UK, 2005.

[25] J. M. Rose and M. C. Bliemer, "Constructing efficient stated choice experimental designs," Transport Reviews, vol. 29, no. 5, pp. 587-617, 2009.

[26] Z. SÁndor and M. Wedel, "Designing conjoint choice experiments using managers' prior beliefs," Journal of Marketing Research, vol. 38, no. 4, pp. 430-444, 2001.

[27] NGENE, Ngene 1.2 User Manual \& Reference guide. The Cutting Edge in Experimental Design, Coiche Metrics, New York, NY, USA, 2018, http://www.choice-metrics.com.

[28] NLOGIT, NLOGIT Version 6. Reference Guide, William H. Greene. Econometric Software, Inc, New York, NY, USA, 2016, http://www.limdep.com/. 
[29] K. E. Train, Discrete Choice Methods with Simulation, Cambridge University Press, Cambridge, UK, 2009.

[30] D. A. Hensher and W. H. Greene, "The Mixed Logit model: the state of practice," Transportation, vol. 30, pp. 133-176, 2003.

[31] K. E. Train, "Recreation demand models with taste differences over people," Land Economics, vol. 74, pp. 230-239, 1998.

[32] E. Cascetta, P. Coppola, and V. Velardi, "High-Speed Rail demand: before and after evidences from the Italian market," DISP The Planning Review, vol. 49, no. 2, pp. 51-59, 2013. 